\title{
Entre canteiros e nuvens, perigos e guarda-chuvas: A experiência de uma pesquisa-intervenção com pessoas em situação de rua
}

Ana Karenina de Melo Arraes Amorim. Universidade Federal do Rio Grande do Norte

Maria Teresa Nobre. Universidade Federal do Rio Grande do Norte

André Feliphe Jales Coutinho. Prefeitura Municipal de João Pessoa

Francisco Emanuel Soares Gomes. Universidade Federal do Rio Grande do Norte

\section{Resumo}

O artigo apresenta uma experiência de pesquisa-intervenção com pessoas em situação de rua, que buscou conhecer suas condições e trajetórias de vida, as violações de direitos sofridas, bem como suas necessidades, projetos e formas de resistência. A inserção no campo de pesquisa ocorreu por meio de uma etnografia. Foram realizadas entrevistas que possibilitaram a construção de um inventário de narrativas. Estas apontam algumas dificuldades enfrentadas pelas pessoas em situação de rua, como o preconceito, o não-lugar na cidade, a fragilidade das políticas públicas, a violência policial, e outras violações de direitos. As narrativas ainda revelam as multiplicidades da vida e as estratégias, táticas e astúcias desenvolvidas por essas pessoas para sua sobrevivência nas ruas. Por fim, destacamos a importância dos vínculos, solidariedades e produção de coletivos como vias emancipatórias em favor da invenção da vida e da luta por direitos humanos que ganham contornos neste contexto.

Palavras-chave: população em situação de rua; pesquisa-intervenção; narrativas; direitos humanos.

\begin{abstract}
Among flower beds and clouds, dangers and umbrellas: The experience of an intervention research with people on the streets. We present a research-intervention experience with homeless on the streets, that sought to know their living conditions and life trajectories, those suffered rights violations as well as their needs, projects and forms of resistance. Entering the research field was through an ethnography. Interviews were conducted that allowed the construction of an inventory of narratives. These point to some difficulties faced by people on the streets, such as prejudice, the non-place in the city, the fragility of public policy, police violence and other rights violations. The narratives also reveal the multiplicity of life and the strategies, tactics and cunnings developed by these people for their survival on the streets. Finally, it highlights the importance of the ties, solidarity and collective production as emancipatory way in favor of invention of life and the struggle for human rights that gain contours in this context.
\end{abstract} Keywords: homeless; action research; narratives; human rights.

\section{Resumen}

Entre flores y nubes, los peligros y los paraguas: La experiencia de una investigación intervención con la gente en las calles. Presentamos una experiencia de investigación-intervención con la gente en las calles, que trató de conocer sus condiciones y trayectorias de vida, esas violaciones de derechos sufridas, así como sus necesidades, proyectos y formas de resistencia. La inserción en el campo de pesquisa fue a través de una etnografía. Se llevaron a cabo entrevistas que permitieron la construcción de un inventario de las narrativas. Estas indican algunas dificultades que enfrentan las personas en las calles, como los prejuicios, el no-lugar en la ciudad, la fragilidad de la política pública, la violencia policial y otras violaciónes de los derechos. Los relatos revelan también la multiplicidad de la vida y las estrategias, tácticas y astucias desarrolladas por estas personas para su sobrevivencia en las calles. Por último, se destaca la importancia de los lazos, la solidaridad y la producción colectiva como forma de emancipación a favor de la invención de la vida y la lucha por los derechos humanos que adquieren contornos en este contexto.

Palabras clave: sin vivienda; investigación-acción; narrativas; derechos humanos. 
O presente artigo apresenta e discute uma pesquisa-intervenção realizada junto a pessoas em situação de rua, que desenvolvemos durante 2 anos, em Natal/ RN, uma capital do nordeste brasileiro. Mas, quem são ou o que significa "pessoas em situação de rua"?

De acordo com o Decreto Lei ${ }^{\circ} 7.053 / 2009$, que institui a Política Nacional para a População em Situação de Rua, considera-se população em situação de rua o grupo populacional heterogêneo que se encontra abaixo da linha da pobreza, tem vínculos familiares rompidos ou fragilizados e, não possuindo moradia convencional regular, utiliza logradouros públicos e áreas degradadas para morar e viver ou faz uso das unidades de acolhimento noturno para pernoite, de modo permanente ou temporário.

Tal definição, embora proponha a superação do estigma do "morador de rua" ainda é insuficiente para definir a complexidade desses modos de existência. Estes, marcados pela multiplicidade de uma itinerância que é, ao mesmo tempo, material e simbólica, nos convocam a recorrer a outro modo de olhar essas pessoas, naquilo que têm de indizível e inalcançável, desalojando-nos das nossas "casas" cognitivas, afetivas, valorativas e morais.

Pensamos, assim, que a uma perspectiva ético-política que produz um outro olhar sobre nós e para os outros, faz-se necessário aliar uma dimensão estética (Guattari, 2012), que nos leve a pensar o trabalho nesse campo como criação e no qual estamos interessados nas insignificâncias, nos abandonos, nos desperdícios, num esforço de fazer ver o invisível e ouvir o inaudito das cidades. Apresentamos fragmentos de um trabalho itinerante, feito de errâncias, "desperdícios" e gratuidades, sobretudo em relação às histórias das vidas "achadas nas ruas".

Para tanto, fazemos um breve panorama acerca da recente política pública para este segmento populacional instituída no Brasil em 2009 e o contexto do seu surgimento. Em seguida, discutiremos a nossa aproximação ao campo problemático, dando destaque às perspectivas teórico-metodológicas que orientam nossas ações e os desafios do encontro com a rua, partindo do pressuposto de que intervir para conhecer passa pela construção de vínculos ou redes. Em primeiro lugar porque é preciso enredar-se: implicar-se, comprometer-se com as pessoas, primeiramente; com os serviços, políticas públicas e equipamentos sociais, depois; quando e se isso for possível. Por fim, discutimos duas histórias de pessoas em situação de rua, obtidas em situação de pesquisa-intervenção, consideradas "emblemáticas", apesar das suas singularidades. As histórias foram escoIhidas por terem mobilizado os pesquisadores no sentido de uma reflexão sobre os modos de fazer pesquisa e de circular no campo.

\section{Justificativa da Pesquisa-Intervenção}

O Estado brasileiro tem uma dívida histórica no que se refere à elaboração de políticas públicas para a população em situação de rua. Entendemos por política pública aquelas políticas que são formuladas a partir das demandas sociais da sociedade civil num Estado democrático. É preciso, entretanto, pensar criticamente as relações entre as políticas públicas e o Estado, uma vez que o estatal e o público têm domínios diversos, sendo o primeiro "uma figura paralisada e transcendente da modernidade" e, portanto, engessada no seu funcionamento, enquanto o segundo "diz respeito à experiência concreta dos coletivos de forças sempre em movimento" (Monteiro, Coimbra, \& Mendonça Filho, 2006, p. 11), carregando, portanto, a possibilidade contínua da mudança.

Nesse sentido, o primeiro modelo de política voltado para esse segmento populacional remonta ao papel de um estado higienista que validava ações repressivas pelos seus agentes. As pessoas que viviam nas ruas eram violentamente retiradas dos centros urbanos, discriminadas e culpabilizadas pela situação em que se encontravam (Ministério de Desenvolvimento Social e Combate à Fome [MDS], 2008).

Na década de 1990 algumas iniciativas de governos municipais começaram a ser pensadas, voltando-se para a proteção e inclusão social dessas pessoas (Brasil, 2008), apesar do contexto de emergência e consolidação da política neoliberal adotada pelo Estado brasileiro. Em 2004, quando lamentavelmente houve o massacre de pessoas em situação de rua na Praça da Sé, no dia 19 de agosto, em São Paulo, os próprios "moradores de rua" iniciaram um processo de articulação e organização nacional, cuja pauta era a luta contra a violência e a impunidade (Ferro, 2012), incorporada na agenda política do governo federal.

Em 2005, o Ministério do Desenvolvimento Social e Combate à Fome (MDS) assumiu a discussão, possibilitando a participação da sociedade civil no debate e formulação de políticas públicas destinadas a esse segmento populacional. Em 2006 foi criado um Grupo de Trabalho Interministerial, abrangendo as áreas da saúde, educação, direitos humanos, habitação e cultura (Ferro, 2012). Três anos depois foi instituída a Política Nacional para População em Situação de Rua, através do Decreto Presidencial 7.053/2009. 
Um marco importante no processo da construção dessa política foi uma pesquisa realizada pelo Ministério de Desenvolvimento Social (MDS) em 2008, que abrangeu 71 cidades brasileiras, sendo 23 capitais. Esse levantamento constatou que nas capitais e cidades com mais de 300 mil habitantes, viviam aproximadamente 50 mil adultos em situação de rua, sem contabilizar crianças e adolescentes (Ferro, 2012). Essas pessoas têm diariamente seus direitos básicos violados e sofrem cotidianamente processos de exclusão e invisibilidade, incluindo a mendicância, drogadição e violência (Soares, 2004).

No estado do Rio Grande do Norte essa realidade não difere. De acordo com a pesquisa do MDS (2008), nele foram contabilizados 223 adultos em situação de rua, mas é possível afirmar que o número atual é bem mais elevado.

$\mathrm{Na}$ capital do estado ( $\mathrm{Natal} / \mathrm{RN}$ ), os serviços disponíveis, criados em 2011, são: uma Unidade de Acolhimento para População em Situação de Rua, três equipes de Consultório na Rua (CnR) na atenção básica do Sistema Único de Saúde e um Centro de Referência Especial de Assistência Social para População em Situação de Rua - Centro Pop, que passou por um longo período de desativação, retomando suas atividades em 2014.

Estar no mundo - e particularmente nas ruas - é viver uma experiência que historicamente coloca seres humanos não rentáveis aos interesses capitalistas hegemônicos em situações de precariedade e violências.

Neste contexto, o Centro de Referência em Direitos Humanos (CRDH) da Universidade Federal do Rio Grande do Norte (UFRN), deparou-se com graves violações aos direitos de pessoas em situação de rua, que vão desde atendimento restritivos e preconceituosos em estabelecimentos públicos até a violência policial e outras formas de violência, preconceito e opressão. De maneira geral, o que se observa no município é que a efetivação de políticas e serviços socioassistenciais destinados a essa população ainda não está de acordo com o preconizado pela Política Nacional para a População em Situação de Rua, como em outros estados brasileiros (Conselho Regional de Psicologia de Minas Gerais, 2015; Kunz, Heckert, \& Carvalho, 2014; Moura, Ximenes, \& Sarriera, 2013). Há um quadro reduzido de instituições e serviços, necessidade de formação continuada dos técnicos que neles trabalham e a falta de ações em rede.

Por sua vez, as universidades no Estado também se mostram distantes de tal contexto, sendo poucos os debates incluídos nos espaços de ensino e reduzido o número de projetos de pesquisa e extensão voltados para esta população. A ação integrada ensino-pesquisa-extensão que realizamos entre 2013 e 2016 vem suprimir essa lacuna na nossa instituição, desdobrando-se em outros projetos, atualmente em curso.

A pesquisa buscou construir um perfil psicossocial dessas pessoas e conhecer suas narrativas sobre modos de viver e/ou estar nas ruas, através de entrevistas semiestruturadas e observações participantes, realizadas por meio da participação em vários eventos e situações. Destacamos para o escopo deste artigo apenas o trabalho realizado com as narrativas.

O projeto adotou a perspectiva teórico-metodológica da pesquisa-intervenção (Aguiar \& Rocha, 2003) e contou com a participação de discentes dos Cursos de Graduação em Psicologia, Direito, História e Serviço Social, articulando-se com ações desenvolvidas pelo $\mathrm{CRDH}$, que atua em parceria com o Movimento Nacional da População em Situação de Rua (MNPR). Além de promover a realização de vários eventos e cursos de formação política, mantivemos uma Oficina de Cidadania como atividade semanal e regular. Em 2014, esse trabalho foi ampliado, tornando-se um dos campos de estágio curricular obrigatório da graduação em Psicologia da UFRN e no qual desenvolveram-se ações sistemáticas, tais como: oficinas e rodas de conversas, participação em audiências públicas, reuniões com gestores e técnicos das Secretarias de Saúde e Assistência Social, apoio ao MNPR, acompanhamento de ações do Consultório na Rua e trabalho de Acompanhamento Terapêutico de alguns usuários em situação de drogadição, além de outras atividades.

As ações propostas caminharam no sentido de enfrentar o desafio contemporâneo indicado por Guattari (2012) ao afirmar que as questões relacionadas à produção da existência humana em nosso contexto histórico estão articuladas a uma crise envolvendo o meio ambiente, as relações sociais e a subjetividade humana. Como saída desse quadro ele propõe uma mudança que critica o paradigma científico e propõe o paradigma estético, afirmando-o na maneira de operar processos de singularização que se aproximam mais do artista que do cientista, uma vez que se propõe a uma experimentação enquanto criação na diferença. A dimensão estética seria uma aposta na invenção de percursos, modos de fazer, na produção de novas formas de subjetivação e realidades, em um compromisso com o movimento contínuo e com o fluxo criativo da vida, aqui entendida como "obra de arte". Trata-se da reinvenção dos sentidos, "da relação do sujeito com seu corpo, com o fantasma, com o tempo que passa, com os 'mistérios' da vida e da morte" (Guattari, 2012, p.16). 
No sentido de produzir essas formações subjetivas esteticamente fundadas no fazer ciência como "intervenção e invenção", na trilha proposta por Guattari (2012), descreveremos, a seguir, a pesquisa-intervenção, focalizando a nossa inserção no campo e o recorte de duas narrativas de vida de pessoas que fazem das ruas o espaço de produção da vida cotidiana.

\section{Método: sobre o campo e modos de fazer pesquisa-intervenção}

O início da nossa ação junto à população em situação de rua se deu como exercício de pesquisa-intervenção, método que se caracteriza pelo processo simultâneo de intervir para conhecer e de conhecer para intervir. Intervenção como criação de um campo de tensão entre a problematização e a invenção ou reinvenção do cotidiano. Esse processo significou para nós formular as questões: quem são essas pessoas, onde estão, o que fazem, o que pensam, onde/como/em que trabalham, quais são suas estratégias e táticas de sobrevivência, como é seu cotidiano e sua vida, quais são suas dores, seus temores, suas alegrias, suas conquistas?

Construir o perfil psicossocial dessa população e conhecer as narrativas sobre suas vidas e trajetórias foi o primeiro movimento do trabalho, seguido simultaneamente de outro. De expectadores passamos a "acoIher-dores" interceptados pela urgência, às vezes sem aviso prévio, de sermos afetados pelo desamparo, pela incerteza, pelas vidas quase morridas, do outro. Mas também pela sua engenhosidade, pela solidariedade, pela capacidade de resistir, pela teimosia em acreditar, pela esperança, pelas suas "astúcias" (Certeau,1999). Para esse autor, as estratégias são ações objetivas, dirigidas a um alvo específico, que poderíamos exemplificar, no caso desta pesquisa, como sendo demandas, denúncias, reivindicações, processos judiciais e outras ações dirigidas ao Estado por pessoas em situação de rua, articuladas em torno de interesses definidos, que acionam dispositivos institucionais. Entretanto, na lida cotidiana, as pessoas apresentam modos de resistência ou enfrentamento mais pontuais, difusos, fluidos e passageiros, aos quais o autor chama de "táticas". Essas são ações miúdas e astuciosas, que privilegiam o tempo e as circunstâncias, aproveitam acasos e jogam com desejos e regras que conseguem driblar, mudar ou criar em determinada situação. Elas escapam ao controle e representam um contrapoder, capazes de conferir pequenas vitórias a quem as utiliza (Certeau,
1999). Foram essas práticas as que mais encontramos no campo. E, assim, nos lançamos a viver a experiência de aproximação dessas vidas e das suas narrativas enquanto "capacidade esquecida e em desuso de trocar experiências" (Benjamin, 1936/2012, p. 216).

Tomamos a narrativa como "uma história expressa numa linguagem aberta", que permite uma livre interpretação de quem a ouve (Chiazzotti, 2014, p. 120) e que tem por base o contexto das interações sociais, nas quais as enunciações produzidas pelos seus protagonistas têm lugar. A construção e análise das narrativas se dá a partir do que nos conta aquele que viveu uma experiência e que ao enuncia-la permite que dela se depreenda o sentido da ação, relativo à história contada (Chiazzotti, 2014). Neste sentido, a construção da narrativa é uma obra de mão dupla, produzida por quem fala e por quem escuta, num movimento ativo de ambos.

Como sugere Walter Benjamin (1936/2012), a narração estabelece elos entre um passado sempre inacabado, o presente em construção e o futuro incerto, o que distancia radicalmente a narrativa da coleta de informações, que caracteriza o relato. Neste, a exigência da verificabilidade da informação limita a comunicação entre quem fala e quem ouve, impondo a necessidade de explicações. Na narrativa, o que se transmite é a vivência, a experiência, que afeta não apenas quem fala, mas quem ouve e a regista, de modo a poder recontá-la, transmitindo, assim, o que foi compartilhado. É neste desafio que se produz a possibilidade de intercambiar experiências, como refere o autor.

A inserção no campo demandou um exercício de toda a equipe de atuar junto à população em situação de rua, sem "autuá-la", escapando do "desejo de polícia" que há em nós, dos nossos gostos pela legalidade, por aquilo que não se desvia, pelos comportamentos e atitudes "normais". Uma prática que começou pelo exercício de nos despirmos dos preconceitos que a maioria da sociedade tem: contra os pobres ("porque são potencialmente criminosos"), contra os loucos ("porque são potencialmente perigosos"), contra os drogados e os bêbados ("porque incomodam"), contra os pedintes ("porque são preguiçosos"), contra os que estão ao léu pelas ruas ("porque são vagabundos e não querem trabalhar").

Para tanto, adotamos a perspectiva etnográfica a fim de construir uma profunda e continuada inserção no campo, que ultrapassa as ações pontuais de aplicar questionários ou realizar entrevistas.

"A etnografia não é algo que se faz espontaneamente" (Peirano, 1995, citada por Sato \& Souza, 2001, 
p. 33). O campo guia a pesquisa a partir da construção do objeto e dos objetivos, na forma de um conhecimento aberto, não estandartizado, porém feito com um rigor que não diz respeito apenas aos aspectos metodológicos, mas à "qualidade do relacionamento entre o pesquisador e as pessoas do local pesquisado" (Sato \& Souza, 2001, p. 36).

O exercício desta atitude requerida pela etnografia foi um valioso recurso no desenvolvimento da nossa pesquisa-intervenção, posto que ambos os métodos têm em comum o pressuposto da realização de um trabalho de campo feito "em situação" (Aguiar \& Rocha, 2003), na qual o próprio pesquisador é parte da experimentação. Participando "de perto e de dentro" (Magnani, 2002) do que acontece no campo, nele se insere por uma aproximação intensa, buscando colocar em evidência tanto o que se repete e se estabelece como prática rotineira, quanto as singularidades que produzem rupturas. Em ambos os métodos é preciso questionar aquilo que parece dado, estranhar o aparentemente familiar, para desnaturalizá-lo e aproximar o estranho, para apreender seus sentidos. Desloca-se, desta maneira, o eixo da macropolítica para a micropolítica, considerando, entretanto, nas relações cotidianas não apenas sua face local, mas sua relação com determinantes sociais e culturais mais amplos (Sato \& Souza, 2002).

Assim, procuramos viver a vida do e no campo, participando de atividades que nele aconteciam, que incluíam desde ações macropolíticas (participação em audiências públicas e fóruns, por exemplo) até, e sobretudo, práticas corriqueiras (como trocar gentilezas, escutar pessoas em situações diversas, compartilhar dificuldades, dores e alegrias).

Assim, exercitamos um olhar para o que está nas margens dos cenários da cidade, invisibilizado no fora que é habitado por essas pessoas. Experimentamos estar à margem, despindo-nos dos desejos de estar "dentro", dos manicômios mentais em nós (Pélbart, 1989).

Uma vez no campo, buscamos modos de abordar as pessoas na situação em que se encontravam: trabaIhando, comendo, conversando, no momento que aguardavam a entrada na Unidade de Acolhimento, após a realização das Oficinas de Cidadania, nas praças e canteiros onde vivem ou se demoram, durante a distribuição de cafés da manhã em uma praça e em uma igreja evangélica, etc. Realizamos 159 entrevistas entre outubro de 2013 e julho de 2015, que tiveram duração variável entre meia hora e uma hora e meia e não foram gravadas.

Sem criar condições excepcionais para entrevistar as pessoas, percebemos que um outro movimento se desenhava e que dizia respeito às relações entre as próprias pessoas que estão em situação de rua. Assim, buscamos aproximar mais essas pessoas entre si, aquelas que cotidianamente se relacionam no espaço da rua (supostamente um espaço público) e aproximá-las de outros espaços (oficinas, fóruns, audiências), criando movimentos de antiprivatização das relações sociais e politização da vida.

Deste modo, esse projeto buscou contribuir no processo de produção de novas subjetividades, como parte de um processo de "construção de si" (Passos \& Barros, 2000). Aqui afirmamos a subjetividade como processo no qual estão implicados o ambiente, a cultura, as relações sociais, os humanos e os não humanos. E, nesse sentido, os ambientes físicos, sociais e simbólicos e as relações entre as pessoas e delas com os lugares e as coisas que as cercam, também constroem o campo da pesquisa.

Essa perspectiva nos ajuda a superar a dicotomia entre sujeito e objeto e a separação entre um dentro (uma suposta "interioridade" daqueles a quem abordamos) e um fora (o pesquisador e a instrumentalização técnica da pesquisa). Deste modo, podemos dizer que mais do que a construção de um perfil psicossocial e de um inventário de narrativas de pessoas em situação de rua, a pesquisa-intervenção caminhou no sentido de favorecer as pessoas que dela participaram canais de expressão das suas angústias e necessidades pessoais e coletivas, assim como a discussão de modos de superação das violações de direitos, como estratégias dirigidas ao Estado, por meio da organização política do MNPR. Ou seja, a experiência da pesquisa-intervenção afirmou um outro modo de conceber o "método" na produção da pesquisa como algo que "não visa a nos fazer conhecer qualquer coisa, mas a nos fazer conhecer a nossa potência de conhecer" (Deleuze, 1986, p. 90).

A inserção dos pesquisadores no campo, inspirados pela perspectiva etnográfica, se fez entre as sutilezas e as persistências do caminhar nos trajetos que se apresentavam como possíveis, nas histórias narradas e nos encontros com as pessoas na rua. Como norte ético, partimos, nas práticas da pesquisa-intervenção, da construção da implicação no campo, do exercício da sensibilidade em estar ao lado e ir, devagar e insistentemente, se interessando pelas vidas ali, naquilo que há nelas de precário, mas também de potente. Procuramos, assim, recusar o lugar da neutralidade na pesquisa, reconhecendo as relações de poder nas instituições e tomando o conceito de "implicação" como referência, entendido 
como objeto de análise das relações do pesquisador com suas instituições de pertencimento que possibilitam a sua inserção nas situações sociais de intervenção, formação e pesquisa (Lourau, 1993).

A seguir, apresentamos as narrativas feitas pelos pesquisadores a partir dos encontros com as histórias de vida de duas mulheres, Lethe e Helena. Com as narrativas, trazemos um recorte das ações e os elementos do processo de conhecer-intervindo, indicando o que produzimos nos encontros na rua e os desafios que nos conduziram nesta experiência.

As entrevistas eram iniciadas com um questionário destinado à construção do perfil psicossocial dos sujeitos. Seguíamos depois um roteiro semiestruturado referente aos itinerários institucionais e modos de vida na rua. As respostas eram registradas por escrito, seguidas da produção de diários de campo, nos quais os pesquisadores registraram suas observações, afetações e o teor das entrevistas realizadas. À medida que encontrávamos no campo pessoas já entrevistadas e que estas compartilhavam conosco novas situações e experiências de vida nas ruas, voltávamos ao registro das entrevistas para acrescentar as informações, as circunstâncias e os sentimentos proporcionados por esses novos encontros. Tanto as entrevistas quanto os diários de campo serviram de subsídio para a discussão e reflexão no grupo da pesquisa a partir de sua apresentação semanal pelos entrevistadores. Além disso, leituras acerca da população em situação de rua, com aprofundamento teórico-metodológico de base para o trabalho e a análise das nossas implicações compuseram o material dos encontros de orientação da pesquisa. A análise dos dados, e particularmente das narrativas, foi construída como um trabalho coletivo de discussões, reflexões e afetações.

Os nomes utilizados nas narrativas a seguir são pseudônimos. No caso da protagonista da primeira narrativa, estabelecemos uma relação entre sua história e uma personagem mitológica, Lethe - divindade grega, que significa "esquecimento". Era um dos rios do "Hades" e qualquer um que tocasse em suas águas vivenciaria plenamente o esquecimento. $O$ nome da segunda protagonista, Helena, foi escolhido aleatoriamente.

\section{Resultados e discussão}

\section{A História de Lethe: Resta "Esquecer" e Costurar Outras Histórias}

Em agosto de 2014, iniciamos uma inserção no campo: um café da manhã oferecido em uma praça, aos sábados, por um grupo de religiosos evangélicos. Ao frequentar sistematicamente esse espaço, como forma de aproximação e vinculação com quem ali se encontrava, reconhecemos que nesse grupo existiam integrantes fixos e outros eventuais; sejam pessoas em situação de rua ou moradores de comunidades pauperizadas próximos da praça. No processo de inserção no campo fomos sendo demandados por esses religiosos a fazer parte das tarefas que desenvolviam, os auxiliando na distribuição da alimentação.

Conhecemos Lethe numa dessas vezes que fomos à praça. Chegamos, como de costume, às 6:30 da manhã e perguntamos se poderíamos ajudar na distribuição do café da manhã. Inicialmente ficamos um pouco desnorteados até sermos colocados na função de passar manteiga no pão. Iniciamos o trabalho, o qual logo demandaram que fosse mais e mais rápido. Pegar o pão, separá-lo dos demais, passar um pouquinho de manteiga agilmente e colocar em cima de uma sacola plástica. Ações repetidas várias vezes. Entramos, assim, numa "linha de produção" no campo. Não sabíamos bem produção do quê, mas insistimos na esperança de que algo mais haveria de acontecer além do "pão nosso de todo sábado! "

Quando terminamos, nos aproximamos de Márcia (uma pessoa em situação de rua já conhecida há meses) que nos apresentou a um grupo de dois homens com roupa justa e expressão de gênero feminino e uma mulher e os convidou a participarem da pesquisa. Eles ficaram desconfiados inicialmente, então, explicamos os objetivos da pesquisa e algumas questões éticas. Depois de respondermos algumas dúvidas, concordaram, dizendo que até as 11:00 horas estariam livres e "era até bom para passar o tempo".

No percurso para outra praça, realizado com Márcia, Marcos (seu companheiro), Lucas, Lethe e Bruno, começou a chover. Abrimos o guarda-chuva e ora abrigávamos um, ora abrigávamos outro. Porém, como a chuva não estava forte, eles não se preocuparam tanto com isso e seguiram o caminho. Quando chegamos à praça, a chuva parou. Lucas usou um papelão para tirar o excesso de água do banco e, após isso, sentamos com ele e começamos a entrevistá-lo. Lethe, Márcia, Marcos e Bruno permaneceram ao redor. Algo significativo nessa entrevista foi o incômodo em comum de todas essas cinco pessoas em "não ter o que fazer na rua" e de como todos relataram que se sentiam incomodados com o fato de "não ter o que fazer na rua". Nesse interim, um desconhecido, catador de material reciclável, chegou perto e perguntou quem éramos nós e o que estávamos fazendo. 
Ao encerrar a entrevista de Lucas, Lethe assumiu o lugar de entrevistada. Logo depois recomeçou a chover, bem mais forte que antes. Abrimos o guarda-chuva e guardamos os questionários. Enquanto pensávamos aonde iríamos, alternamos algumas vezes quem ficava debaixo do guarda-chuva, entre as várias pessoas ao redor. Decidimos nos abrigar em frente a um hospital, perto dali. Passamos por um segurança e ali continuamos a entrevista, em pé.

Na primeira pergunta que fizemos, relacionada à idade, Lethe nos causou espanto dizendo que não se lembrava e entregou a sua carteira de identidade para constatar: 38 anos. No decorrer da entrevista outros "esquecimentos" da sua vida apareceram, sempre com um pouco de incômodo de Lethe. Ela não lembrava onde nasceu e também há quanto tempo estava em situação de rua. Tentou responder, sem êxito, evocando períodos de tempo totalmente destoantes entre si. Também não se lembrava do nome da empresa que recusou a lhe dar emprego por estar em situação de rua. Por fim, não conseguiu definir a qualidade do vínculo com seus familiares, objetivamente. Também ficou um pouco inquieta com essa questão e se amparou na imprecisão: "[...] às vezes é boa e às vezes é ruim [...]".

A história, as vinculações e as rupturas na sua trajetória de vida, também foram mencionadas. Lethe afirmou ser mulata, católica e divorciada de um homem com quem "se juntou". Ela não sabe ler nem escrever. Está há 8 anos residindo em Natal/RN. Os motivos que a levaram às ruas foram as agressões do ex-marido, a falta de condições financeiras e a ruptura dos vínculos familiares, motivações diversas apontadas também por outros estudos (MDS, 2008).

Ela sobrevive pedindo dinheiro. Também relatou que "nunca trabalhou de carteira assinada". É dependente química de álcool e nicotina. Não recebe qualquer benefício do governo e não se lembrava do CRAS ou de outros serviços da Assistência Social, com exceção da Unidade de Acolhimento, de modo semelhante a outras pessoas entrevistadas, evidenciando a distância destas políticas, que deveriam ser públicas, das vidas de pessoas na rua.

Outra questão apontada por Lethe, e que diz respeito ao preconceito por ela sofrido nas ruas foi o fato de ter sido impedida de entrar em vários lugares: em estabelecimento comercial, em shopping center, em transporte coletivo, em banco e em serviços públicos. Esses impedimentos revelam que existem interditos no caminhar de Lethe que vão muito além do esquecimento e revelam as práticas de exclusão e marginalização operadas na cidade, nas normas implícitas e explícitas sobre a circulação nos espaços que são, em muitas situações, mediadas pelo mundo do trabalho do qual muitas pessoas na condição de Lethe estão afastadas. "As pessoas me mandam trabalhar, mas a principal dificuldade de quem está na rua é a falta de trabalho, que não tem". Para ela, se deveria "dar oportunidade pra gente trabaIhar. Ter condição de sair da rua". Assim, fora do mundo do trabalho, Lethe perambula pela cidade ocupando um espaço de ausência de história, de identidade, cuja emergência determina a precariedade, a disciplina e o controle, fixando Lethe na margem da cidade.

Após o término da entrevista, agradecemos. A chuva recomeçou e ela foi se abrigar num teatro, junto com outras pessoas em situação de rua. Depois de conversar com Lucas e Bruno nos dirigimos a ela para agradecer novamente, e para refazer o convite para as reuniões semanais em prol da organização coletiva das pessoas em situação de rua. Ainda mencionamos o projeto de alfabetização que ocorria na Unidade de Acolhimento e era ofertado a quem acessava esse serviço. Despedimo-nos, ela sorriu.

Esse foi um encontro, em um dia nublado, com uma mulher que sofreu violência doméstica, que se queixava de falta de atividades para ocupar o tempo e que se sustentava subjetivamente com o álcool e a nicotina - para ela algo que a distinguia de usuários de substâncias psicoativas ilegais. Nesse encontro, suas memórias pareciam estar, tal qual o tempo, "nubladas". Experimentar com ela essa nublagem, faz pensar que faz pensar que é preciso falar sobre si e refazer as costuras dos pedaços de uma história de vida para minimizar os efeitos do esquecimento, produzidos nos tempos e espaços outros da própria biografia, que inclui, em determinado momento, a vida na rua. Ao escutar, oferecemos um guarda-chuva real e simbólico, no qual, temporariamente, se abrigam as histórias das vidas à medida que são narradas. A vida só se projeta adiante quando se consideram as trajetórias que contribuíram com o enquadre do presente e então outros mundos e histórias vão sendo possíveis, em certa medida, desfazendo as "margens" de exclusão rigidamente colocadas para as pessoas em situação de rua.

O encontro com Lethe aconteceu apenas uma vez. Logo, essa nublagem ainda pode estar se produzindo, caso não tenha encontrado outro(s) que também esteja(m) disposto(s) a oferecer "guarda-chuvas" para que vivências, sejam dolorosas ou alegres, precipitem novos movimentos afirmadores da vida, contágios e 
perturbações, rompendo as represas ou margens instituídas no "esquecimento".

$\mathrm{O}$ encontro com Lethe nos permite afirmar que a rua é "esquecida" e relegada como a morada da insegurança, do inesperado e da incerteza, elementos presentes na narrativa de Lethe e que também permearam nosso encontro, marcado por instabilidades, tentativas e buscas que nos interpelaram a tentar outros modos de aproximação das pessoas e a criar condições possíveis para a realização das entrevistas, num dia de chuva, sem abrigo, sem teto, sem lugar.

A insegurança, o inesperado e a incerteza das ruas "contaminaram" o próprio campo disciplinar, desfazendo as linhas de uma Psicologia "segura", nos interpelando e desafiando como psicólogos e psicólogas na e em formação, nos instigando a questionar nossas estabilidades subjetivas. A pesquisa-intervenção provocava em nós tentativas de lidar com as impotências, as precariedades e os sofrimentos das pessoas em situação de rua de quem nos aproximávamos. Porém, os desafios que aí se colocaram produziram a possibilidade de criar novas ações, com o uso das nossas "caixas de ferramentas" (teórico-conceituais, metodológicas e técnicas) mas sem scripts pré-determinados "do que fazer".

Assim, foram mobilizadas algumas articulações com as políticas públicas e com a rede de garantia de direitos existente, compartilhando informações sobre essa rede, às vezes no ato da entrevista e também no decorrer da presença semanal no campo. Em outras situações, acompanhamos algumas pessoas em seus itinerários institucionais, negociando acessos e fornecendo informações que não dispunham. Outras ações, embora relacionadas às pessoas, não se limitavam ao âmbito individual, pois consistiram no fomento de espaços coletivos, como resistência ao "esquecimento", às omissões, preconceitos, violências e violações de direitos humanos que envolvem a situação de rua. Tal resistência "em fazer lembrar" se dava a partir da implicação de certas pessoas em situação de rua, militantes, pesquisadores, extensionistas, estudantes e profissionais (por vezes, borrando esses lugares identitários) em determinadas ações, como: rodas de conversa e oficinas, algumas motivadas por falas de "não ter o que fazer na rua"; reuniões e eventos do MNPR; audiências públicas e fóruns; participação no controle social (conselhos e conferências relacionadas às políticas públicas), dentre outros espaços acadêmico-políticos.

Aprendemos a partir desse e de outros encontros que é possível produzir uma outra formação em psicologia, à medida que os discentes-pesquisadores vão ao encontro do campo produzindo movimentos de implicação, pensamento e vida. Assim, fazemos eco ao que propõe Barros e Barros (2007): "o que buscamos potencializar nos processos de formação são as formas de ação que produzem movimentos afirmadores da vida, que fomentam contágios e perturbação nos processos instituídos" (p. 77) e nos processos de esquecimento.

A história de Helena: as dores abrigadas num canteiro, desfazendo instituídos em nós.

Helena é uma mulher de 26 anos, magra, baixa, de cabelos grandes e cacheados que conhecemos, em uma das idas a campo, em frente à Unidade de Acolhimento. Em nosso primeiro contato, estávamos sentados na calçada, num fim de tarde, quando ela chegou, aparentemente cansada e carregando uma sacola plástica transparente com papéis e documentos. Usava roupas sujas e fumava. Ao se aproximar, perguntou o que estávamos fazendo ali, pois tinha percebido que não éramos "moradores de rua" e estávamos portando papéis (os questionários da pesquisa). Após explicar quais eram os objetivos de nossas idas àquele lugar, começamos a conversar sobre a situação de rua e as dificuldades enfrentadas por quem se encontra na condição de grande vulnerabilidade, sobretudo quando se é mulher.

Como estudou até a $3^{a}$ série do Ensino Fundamental e sabe ler e escrever, ao aceitar participar da pesquisa, fez questão de ler na íntegra todo o Termo de Consentimento Livre e Esclarecido da pesquisa. Percebemos que estabelecíamos com ela um vínculo de confiança ao dizer que a entrevista poderia ser interrompida a qualquer momento e que ela não seria obrigada a nos falar sobre o que não quisesse.

Helena, então, se sentiu à vontade para falar. Ela é natural de Natal/RN e está em situação de rua desde seus 8 anos de idade, época na qual sofria abuso sexual do seu padrasto, até os dias atuais. Ela disse também que estava dormindo na Unidade de Acolhimento, porque estava cumprindo uma ordem judicial, pois para ter seu filho de 6 meses de volta, o qual encontrava-se numa Casa de Passagem, precisava obedecer a essa ordem, além de ter de passar o dia inteiro no Centro de Atenção Psicossocial - Álcool e outras Drogas (CAPS-AD) para se tratar da dependência química, outra exigência do juiz.

Helena também contou que enfrenta alguns problemas de saúde, como tuberculose, asma e depressão. Além da situação de rua, consome maconha, craque, cocaína, cigarro e bebidas alcoólicas. Helena lamentou bastante o fato de ter andado o dia inteiro em busca 
de atendimento na rede de saúde da cidade e não ter conseguido. Falou que tem se esforçado para seguir à risca o tratamento contra a tuberculose, mas não tem tido o apoio dos próprios serviços de saúde. Disse que foi ao posto de saúde do bairro, mas lá estavam em greve e mandaram-na para um hospital geral e, de lá, encaminharam-na para outro hospital, especializado em quadros infecciosos. E, em momento algum, os profissionais desses serviços "se preocuparam em como chegaria a esses lugares doente e sem dinheiro". Nesse dia, pediu ajuda a um amigo cadeirante para chegar até esses locais, porque acompanhando essa pessoa poderia entrar gratuitamente nos ônibus. Eis uma das "astúcias" de Helena, no sentido atribuído por Certeau (1999), para sobreviver à precariedade financeira e poder circular pela cidade, o que também revela pequenas redes de solidariedade entre as pessoas na rua.

O valor do Bolsa Família que está em seu nome não chega às suas mãos, porque sua mãe é quem o recebe, pois cuida de seus filhos de 12 e 3 anos. Um outro de 6 anos mora com o pai. Para sobreviver nas ruas, Helena vende coisas na feira, cata materiais recicláveis, faz faxina e pede dinheiro às pessoas. Assim como Lethe, nunca trabalhou com carteira assinada, mas não tem enfrentado dificuldades para se alimentar, pois toma café e janta na Unidade de Acolhimento, e almoça na rua. Helena revela aqui que, diferentemente das representações sociais acerca das pessoas em situação de rua, estas trabalham muito, porém sem vínculo empregatício formal, o qual, em muitos casos, nunca foi efetivado durante toda a vida.

Apesar de ser negra, pediu para registrar que é branca, pois é isso que sua certidão de nascimento afirma. Mostrou o documento. Já foi evangélica e não frequenta mais a igreja, mas ainda se considera como tal e pediu para que registrássemos isso. Em alguns desses momentos, pensamos estar sendo testados quanto ao que fora dito a ela no início da nossa entrevista: a garantia de que o questionário seria preenchido de acordo com o que ela dissesse.

As experiências de violência policial que sofreu engrossam a trilha da vida desconfiada. Contou que certa vez: "estava na Praia do Meio consumindo drogas e, apesar de estar muito machucada, porque tinha me envolvido numa confusão e tinha sido agredida na barriga com uma garrafa de vidro quebrada, policiais da ROCAM me abordaram e me deram muitos choques com armas usadas pra isso". Disse que não registrou a ocorrência porque acredita que "tem de agradecer a Deus por estar viva", visto que esta não é a sorte de muitos que os policiais abordam com truculência. É essa violência que Helena disse mais temer nas ruas, como também afirmaram muitos outros que entrevistamos. $\mathrm{O}$ temor vem de onde deveria vir segurança e proteção. $\mathrm{E}$, assim, Helena nos faz inverter uma lógica, nos faz rachar preconceitos, desfazer as representações instituídas sobre a periculosidade na rua, voltada agora para os profissionais que deveriam nos garantir proteção. A truculência policial, as armas contra desarmados, nos fazem constatar que é o Estado o principal violador de direitos!

Do nosso primeiro contato, ficou a impressão de que Helena tinha um riso sem alegria, parecia estar muito triste. Mesmo assim, era perceptível sua vontade de viver e, principalmente, de conseguir ter seu filho de volta. Posteriormente, tivemos outros contatos com Helena, o que proporcionou a construção e o estabelecimento de vínculo com ela, mas em local diferente de onde nos encontramos pela primeira vez. Nossos outros encontros ocorreram num local, denominado por seus "moradores" de "Canteiro. Ao revê-la, lembramos de sua surpresa ao se dar conta de que não havíamos esquecido seu nome.

Continuamos indo frequentemente ao Canteiro, que havia se tornado um novo campo da pesquisa. Numa dessas vezes Helena nos chamou para conversar. Nitidamente, estava sob o efeito de drogas. Ficamos em pé próximos ao Canteiro. Ela pediu um favor e, por um tempo, não conseguimos entender o que ela dizia, porque sua voz estava embargada. Tentamos ajudá-la a organizar seu discurso enfrentando o desafio de escutar alguém sob efeitos de drogas e aos poucos entendemos o que ela queria que fizéssemos. Dissemos que estávamos percebendo que ela estava tendo dificuldade para se expressar e, ainda, que parecia que queria chorar. Nesse instante, ela, de fato, começou a chorar e pediu outro favor que tinha a ver com seu filho de 6 meses. Ficamos muito comovidos, principalmente porque já conhecíamos um pouco da história da sua vida e nossas afetações têm a ver com a vinculação a essas pessoas. No primeiro encontro, não havíamos nos afetado de forma tão intensa como nesta vez.

Após chorar e ficar calada por uns instantes, Helena falou sobre sua infância e de seu receio quanto ao fato de sua filha morar com o padrasto e sua mãe, temendo que ocorram com a filha os abusos sexuais que ela sofreu. Relembrou alguns momentos de sua infância de forma leve e engraçada e, em outros momentos, falava coisas aparentemente desconexas, mas que 
tinham um sentido quando considerada sua história de vida, o que nos convoca a prestar uma escuta atenta e implicada em qualquer situação, até mesmo naquelas em que estamos diante de alguém sob o efeito de álcool e/ou outras drogas. Se não soubéssemos nada sobre sua história, talvez achássemos que ela estava "delirando" ou só estivesse falando o que disse porque tinha bebido ou consumido drogas. Aqui mais uma rachadura, mais uma "dobra" no pensamento e nos modos instituídos de "fazer escuta" na pesquisa e na clínica.

Tomamos Deleuze (2012) como referência para pensar neste encontro com Helena. Para esse autor, pensar não é o exercício natural de uma faculdade mental, mas é fruto da contingência dos encontros que nos "forçam a pensar". Nesse sentido, só pensamos raramente e sempre a partir da força de algo que nos impele, nos cria a necessidade do ato de pensar, ou seja, o pensar se produz a partir de algo que se "dobra", que exige outros modos de ver e dizer alguma coisa, quando uma nova composição de forças se instaura nas nossas relações com as referências instituídas. Acostumados a escutar "os anormais" para normalizá-los em "condições normais", em settings dados da clínica psicológica no sentido estrito ou na pesquisa não interventiva, o encontro com Helena nos convocou a legitimar sua fala, sua expressão, precisamente porque estava numa condição "desviante, anormal" que exigia cuidado "redobrado". Atenção produzida em pé, no tumulto de um canteiro entre ruas de tráfego intenso, muito distante dos settings tradicionais afeitos à profissão de psicólogo e do pesquisador. Não podíamos ali reproduzir o instituído que desqualificava sua fala por sua condição de intoxicação por drogas e nos furtar a buscar sentido na sua história entregue a nós a partir do vínculo, da confiança.

O encontro com Helena permite pensar que a situação de rua desafia a normalidade da cidade (Venturini, 2009), impondo as "anormalidades" do uso de álcool e drogas, dos adoecimentos físicos e mentais, das deficiências, das carências. Assim, as pessoas em situação de rua convidam a cidade a se "desinstitucionalizar", a desfazer suas margens, e convocam a vida social capitalista a questionar seus limites civilizatórios que reproduzem cotidianamente tantas violências e perversões. Pela sobrevivência nessas margens, os espaços da cidade são subvertidos e desinstitucionalizados em seus usos e formas de ocupação. Helena e seus companheiros de rua criaram uma "casa sem paredes", nos revelando a possibilidade de construir cidades e vida social sem as paredes de exclusão e a necessária organização das pessoas em situação de rua frente à ausência de políticas públicas de acolhida. Com eles, percebemos que é preciso "reabilitar a cidade" no sentido de tornar-se lugar que acolhe, como defende Venturini (2009): "onde é possível a troca de identidades, a criatividade, onde é perceptível uma razão comum para fundamentar a emancipação e a liberdade. É a utopia da cidade vivível e hospitaleira" (p. 219).

\section{Considerações finais}

As narrativas apresentadas nos mostram a riqueza de dados sobre a vida na rua que merece, ainda, análises mais aprofundadas e que acompanhem a complexidade que the constitui. Os encontros na rua nos mostram uma vida de multiplicidades, ao contrário das nossas representações, homogeneidades e generalizações que, por vezes, nos faziam supor histórias iguais. Múltiplas são as motivações e os caminhos que levam a viver na (e da) rua. Múltiplas são as relações com o álcool e as drogas. Múltiplas escolaridades, demandas de saúde, relações com o trabalho, relações com a família. Múltiplos ainda são os modos de viver, entre as astúcias, as táticas e estratégias para sustentar a vida na rua e dela usufruir possibilidades. Os deslocamentos ou fixações de territórios também revelam variações de movimento na rua. Os usos dos espaços públicos subvertem muitas vezes os usos tradicionais e se fazem formas encontradas de abrigo, alimentação, higiene e lazer. O trabalho aparece de alguma forma na vida de quase todas as pessoas e nos desejos de muitos.

Com Lethe, Helena e tantos outros, percebemos que vínculos de amizade e amor são formados na rua, assim como redes solidárias quase imperceptíveis, tanto quanto indispensáveis. Fios de vinculação e confiança há muito perdidas entre tantas violências sofridas. Solidariedade que faz furos nas negligências das políticas públicas. Como saída para as violências e omissões do Estado está a produção de coletivos, caminho percorrido entre muitos obstáculos. O movimento social da população de rua ganha contornos nas ações coletivas como rodas de conversa, oficinas, fóruns e encontros, que têm politizado o trabalho do movimento, facilitando a comunicação dos participantes com setores mais amplos da sociedade, desmistificando preconceitos e fomentando encontros, espaços de escuta, trocas de experiências e saberes e produção de vínculos. Nesse sentido, a produção do coletivo não aparece como agrupamento de 
pessoas que estabelecem consensos, mas como um plano no qual se coengendram o individual e o social, produzido no interstício dessas duas dimensões, plano de mudança e de movimento (Escóssia, 2009). No caso do trabalho junto ao MNPR isso tem sido experenciado pelo fomento à criação de redes de apoio formais e informais, pela convivência com a diferença e pela produção de autonomia, somente viabilizados quando se rompe com os instituídos e se aposta na criação do novo, da resistência e da solidariedade entre os mais invisíveis da cidade. Ações que produzem subjetividades individuais e coletivas, indissociadas entre si.

$\mathrm{Na}$ experiência desta pesquisa-intervenção, seguimos com o desafio de fomentar encontros, produzindo coletivos e sem perder de vista as singularidades de cada história, intercedendo em favor da invenção da vida e da garantia dos direitos de todos os humanos, lá onde as potências e a dignidade pedem lembrança, lugar e passagem.

\section{Referências}

Aguiar, K., \& Rocha, M. (2003). Pesquisa-intervenção e a produção de novas análises. Psicologia: Ciência e Profissão, 23(4), 64-73. doi: 10.1590/S1414-98932003000400010

Barros, M. E. B., \& Barros, R. B. (2007). A potência formativa do trabalho em equipe no campo da saúde. In R. Pinheiro, R. A. Mattos, \& M. E. B. Barros (Orgs), Trabalho em equipe sob o eixo da integralidade: valores, saberes e práticas (pp. 75-84). Rio de Janeiro: CEPESC.

Benjamin, W. (2012). Magia e técnica, arte e política: ensaios sobre literatura e história da cultura. São Paulo: Brasiliense. (Obra original publicada em 1936)

Chiazzotti, A. (2014) Pesquisa qualitativa em Ciências Sociais e Humanas. Petrópolis: Vozes.

Conselho Regional de Psicologia de Minas Gerais. (Org.). (2015). A Psicologia e a população em situação de rua: novas propostas, velhos desafios. Belo Horizonte: CRP 04

Decreto n. 7.053. (2009, 23 de dezembro). Institui a política nacional para a população em situação de rua e seu comitê intersetorial de acompanhamento e monitoramento, e dá outras providências. Brasília, DF: Casa Civil. Recuperado de http://www.planalto.gov.br/ ccivil_03/_Ato2007-2010/2009/Decreto/D7053.htm
Deleuze, G. (1986). Conversações. Rio de Janeiro: Editora 34.

Deleuze, G. (2012). A Dobra, Leibniz e o Barroco. São Paulo: Papirus.

Escóssia, L. (2009). O coletivo como plano de criação na Saúde Pública. Interface - Comunicação, Saúde, Educação, 13(Suppl. 1), 689-694. doi: 10.1590/S1414-32832009000500019

Ferro, M. C. T. (2012). Política nacional para população em situação de rua: o protagonismo dos invisibilizados. Revista Direitos Humanos, 8, 35-39. Recuperado de http://dh.sdh.gov.br/download/conferencias/revista8.pdf

Guattari, F. (2012). As três ecologias. São Paulo: Papirus.

Kunz, G. S; Heckert, A. L; \& Carvalho, S. V. (2014). Modos de vida da população em situação de rua: inventando táticas nas ruas de Vitória/ES. Fractal: Revista de Psicologia, 26(3), 919-942. doi: 10.1590/1984-0292/1192

Lourau, R. (1993). Análise institucional e práticas de pesquisa. Rio de Janeiro: NAPE/UERJ.

Magnani, J.G.C. (2002). De perto e de dentro: notas para uma etnografia urbana. Revista Brasileira de Ciências Sociais, 17(49), 11-29. doi: 10.1590/S0102-69092002000200002

Ministério de Desenvolvimento Social e Combate à Fome (2008). Pesquisa nacional sobre população em situação de rua. Brasília: MDS/Meta Instituto de Pesquisa de Opinião.

Monteiro, A.; Coimbra, C. M., \& Mendonça Filho, M. (2006). Estado democrático de direito e políticas públicas: estatal é necessariamente público? Psicologia \& Sociedade, 18(2), 7-12. doi: 10.1590/ S0102-71822006000200002

Moura, J. F; Ximenes, V., \& Sarriera, J. (2013). Práticas de discriminação às pessoas em situação de rua: histórias de vergonha, de humiIhação e de violência em Fortaleza, Brasil. Revista de Psicologia, 22(2), 18-28. doi:10.5354/0719-0581.2014.30850

Passos, E., \& Barros, R. B. (2000). A construção do plano da clínica e o conceito de transdisciplinaridade. Psicologia: Teoria e Pesquisa, 16(1), 71-79. doi: 10.1590/S0102-37722000000100010

Pélbart, P. (1989). Da clausura do fora ao fora da clausura: loucura e desrazão. São Paulo: Brasiliense.

Sato, L.; \& Souza, M. P. R. (2001). Contribuindo para desvelar a complexidade do cotidiano através da pesquisa etnográfica em Psicologia. Psicologia USP, 12(2), 29-47. doi: 10.1590/ S0103-65642001000200003

Soares, L. E. (2004). Juventude e violência no Brasil contemporâneo. In L.E. Soares \& P. Vannuchi (Orgs.), Juventude e sociedade: trabalho, educação, cultura e participação. São Paulo: PersevAbrario.

Venturini, E. A. (2009). A cidade dos outros. Fractal: Revista de Psicologia, 21(2), 203-222. doi: 10.1590/S1984-02922009000200002 
Ana Karenina de Melo Arraes Amorim, Doutorado em Psicologia Social pelo Programa de Pós-Graduação em Psicologia da Universidade Federal do Rio Grande do Norte (PPgPsi - UFRN), é Professora Associada I do Departamento de Psicologia da UFRN e do PPgPsi/UFRN. Endereço para correspondência: UFRN - Centro de Ciências Humanas, Letras e Artes - Departamento de Psicologia,

Campus Universitário BR-101 - Lagoa Nova - Natal/RN - CEP 59072-970. Telefone: (84)33422236. E-mail: akarraes@gmail.com

Maria Teresa Nobre, Doutorado e Pós-Doutorado em Sociologia pela Universidade Federal do Ceará (UFC), é Professora Associada

IV do Departamento de Psicologia da UFRN e do PPgPsi/UFRN.

E-mail: tInobre@hotmail.com

André Feliphe Jales Coutinho, Graduado em Psicologia pela Universidade Federal do Rio Grande do Norte (UFRN), é Residente Multiprofissional em Saúde da Família e Comunidade da Prefeitura Municipal de João Pessoa (RMSFC da Prefeitura de João Pessoa),

E-mail: andrefeliphepsi@gmail.com

Francisco Emanuel Soares Gomes, Mestrado em Psicologia Clínica pelo Programa de Pós-Graduação em Psicologia da Universidade Federal do Rio Grande do Norte (PPgPsi - UFRN).

E-mail: emanuel.gomespsi@gmail.com

Recebido em 30.Mai.16 Revisado em 23.Jun.17

Aceito em 04.Dez.17 